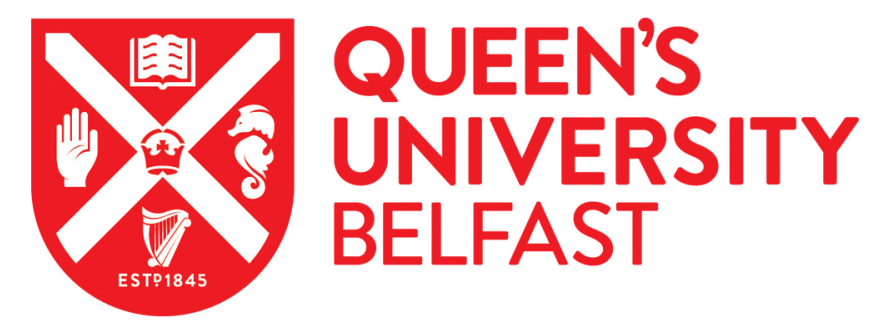

\title{
A cross-sectional comparison of direct medical care costs among COPD and asthma patients living in the community in Northern Ireland
}

Murtagh, N. V., McAllister, D., Kee, F., MacMahon, J., \& Heaney, L. G. (2006). A cross-sectional comparison of direct medical care costs among COPD and asthma patients living in the community in Northern Ireland. Treat Respiratory Medicine, 5(6), 1-8.

Published in:

Treat Respiratory Medicine

Queen's University Belfast - Research Portal:

Link to publication record in Queen's University Belfast Research Portal

\section{General rights}

Copyright for the publications made accessible via the Queen's University Belfast Research Portal is retained by the author(s) and / or other copyright owners and it is a condition of accessing these publications that users recognise and abide by the legal requirements associated with these rights.

\section{Take down policy}

The Research Portal is Queen's institutional repository that provides access to Queen's research output. Every effort has been made to ensure that content in the Research Portal does not infringe any person's rights, or applicable UK laws. If you discover content in the Research Portal that you believe breaches copyright or violates any law, please contact openaccess@qub.ac.uk. 


\title{
A Cross-Sectional Comparison of Direct Medical Care Costs among COPD and Asthma Patients Living in the Community in Northern Ireland
}

\author{
((Author: please insert first names of all authors; initials alone are not sufficient, thanks.)) E. Murtagh, ${ }^{1}$ \\ C. O'Neill, ${ }^{2}$ D. McAllister, ${ }^{2}$ F. Kee, ${ }^{3}$ J. MacMahon ${ }^{1,4}$ and L.G. Heaney((Author: please confirm that you are \\ happy for us to publish your e-mail address) $)^{1,4}$ \\ 1 Regional Respiratory Centre, Belfast City Hospital, Belfast, Northern Ireland \\ 2 School of Policy Studies, University of Ulster Jordanstown, Newtownabbey, Northern Ireland \\ 3 Department of Epidemiology \& Public Health, Queen's University Belfast, Belfast, Northern Ireland \\ 4 Department of Medicine, Queen's University Belfast, Belfast, Northern Ireland
}

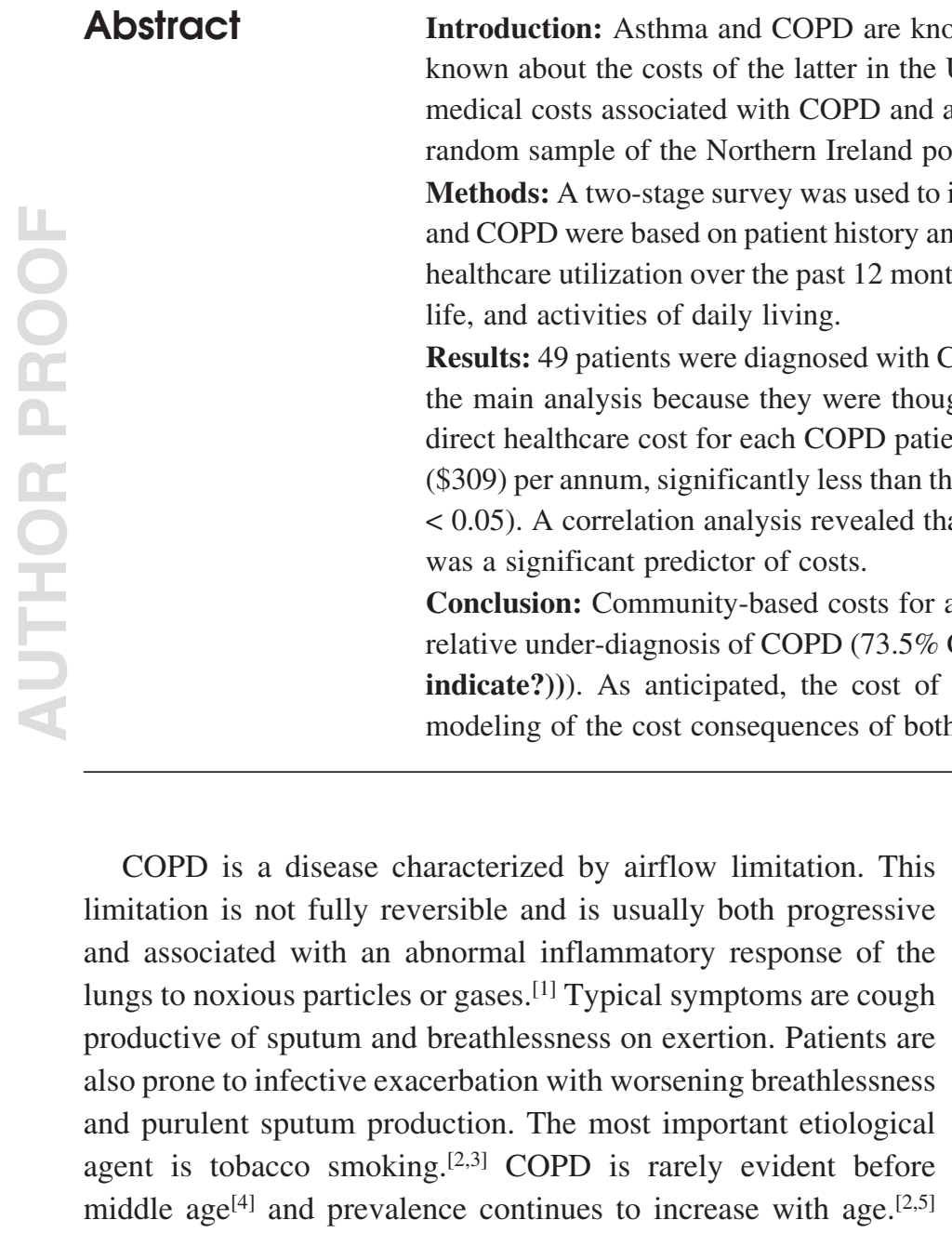

Apart from smoking cessation, no intervention has been shown to alter the decline in lung function in COPD, and current treatments are directed at relieving symptoms, reducing complications, and improving the patient's quality of life.

In contrast to COPD, asthma affects all age groups, with highest prevalence among children. ${ }^{[6-8]}$ It is characterized by variable airflow, bronchial hyperresponsiveness, and eosinophilic inflammation in the airways. Typical symptoms are cough and shortness of breath with wheeze. Individuals with asthma are also 
prone to exacerbation with increasing symptoms. ${ }^{[6,7]}$ Unlike COPD, current asthma treatments can have a dramatic effect on both morbidity and mortality.

Significant health and economic consequences accompany both diseases. In the US an estimated 15 million persons have been diagnosed with COPD, with as many as 16 million more thought to be undiagnosed. ${ }^{[9]}$ It is the fourth leading cause of death (resulting in more than 112000 fatalities in $1998^{[10]}$ ) and is estimated to have resulted in \$US6.6 billion in direct medical costs in $2000^{[11]}$ and upwards of \$US15.5 billion ${ }^{[12]}$ in direct and indirect healthcare costs in 1993. By comparison, in 1998 in the US an estimated 11.9 million persons had experienced an asthma attack in the past 12 months ${ }^{[13]}$ (this being the criterion used to define active asthma) and 4269 patients died of the condition in the US in 2001. Direct and indirect costs (including lost productivity) associated with the disease in the US were estimated at between \$US6 billion ${ }^{[14]}$ and \$US11 billion ${ }^{[15]}$ in 1987 (both costs expressed in year 1994 dollars). Research in several other countries has reported similarly high rates of morbidity and cost associated with both diseases. ${ }^{[16-21]}$ Studies have also shown cost of illness to increase with disease severity in both asthma and COPD. ${ }^{[2,20]}$

In the UK, two studies have examined the cost associated with managing COPD. ${ }^{[22,23]}$ These annual costs were estimated to be $£ 817.5$ million (or $£ 126$ per patient) at year 1996/97 prices and $£ 819.42$ at year $2000 / 01$ prices. The former study was based on a subgroup analysis of data collected in the years 1992/93 where COPD was identified using ICD-9 codes. As recognized by the author, the study is likely to underestimate current costs because of the diagnostic uncertainty regarding COPD in the database used. The latter study relied on a telephone survey, in which a self-reported diagnosis or the presence of symptoms or both were used to identify patients. Again, the basis of diagnosis is potentially problematic because no objective criteria were used to substantiate the diagnosis of COPD. In this study, we report the results of a comparison of the direct medical costs associated with COPD and asthma where diagnoses are based on a robust prevalence study of a random sample from the Northern Ireland population. ${ }^{[24]} \mathrm{We}$ focus on direct costs because these are of fundamental concern to healthcare policy makers and because direct cost data are likely to be captured more robustly.

\section{Materials and Methods}

The survey was designed in two stages. In stage 1 a postal screening questionnaire concerning respiratory symptoms was sent to a random sample of the general population. In stage 2, a sample of the respondents completed a detailed questionnaire on symptoms, co-morbidities, and medication use as well as perform- ing spirometry with reversibility, skin allergy testing, and serial peak flow measurements.

\section{Stage 1}

\section{Population Sampling}

The Queen's University Belfast Research Ethics Committee granted approval for the study. Eligible subjects were selected from the general population in two areas in Northern Ireland: (i) North and West Belfast; (ii) North Down and Ards. These electoral areas have a population of approximately 140000 each, and represent urban and semi-rural environments, respectively. Eligible subjects were Caucasian men and women aged 40-69 years who were non-resident in an institution. A random sample of 4000 individuals, 2000 from each area, were selected from the Master Patient Index of the Eastern Health and Social Services Board (the health authority area in which these regions are located). This database contains all those who have been registered with a general practitioner within the health board area. In May 2000 a short questionnaire, consisting of nine items including questions derived from the Medical Research Council (MRC) Respiratory Symptoms Questionnaire and the MRC Dyspnoea Scale, ${ }^{[25]}$ was sent by post and was self-administered. To maximize response, a second mailing was sent to non-responders 6 weeks after the first mailing. Respondents were divided into 'symptomatic' and 'asymptomatic' groups according to responses. 'Symptomatic' was defined as positive for MRC Dyspnoea Scale grade 2 or higher. Of the 4000 individuals who were sent questionnaires, $67 \%$ responded ( $\mathrm{n}=2484$; 994 symptomatic and 1490 asymptomatic).

\section{Stage 2}

\section{Population Sampling}

Of positive respondents, 1330 (614 symptomatic and 716 asymptomatic) were randomly invited to allow a visit at home by the respiratory nurse to perform the assessment. When an individual was not contactable or refused a home visit, another patient was randomly selected from the appropriate group (380 individuals were not contactable due to absent phone company listing; 152 with a phone listing were not contactable after four attempts; 25 had invalid spirometry; 47 refused to participate; 4 were deceased). A home visit assessment was completed in 722 individuals (326 symptomatic, 396 asymptomatic; see figure 1 for further details).

\section{Home Visit Assessment}

After written consent was obtained, patients completed a nonvalidated questionnaire concerning symptoms and medical histo- 


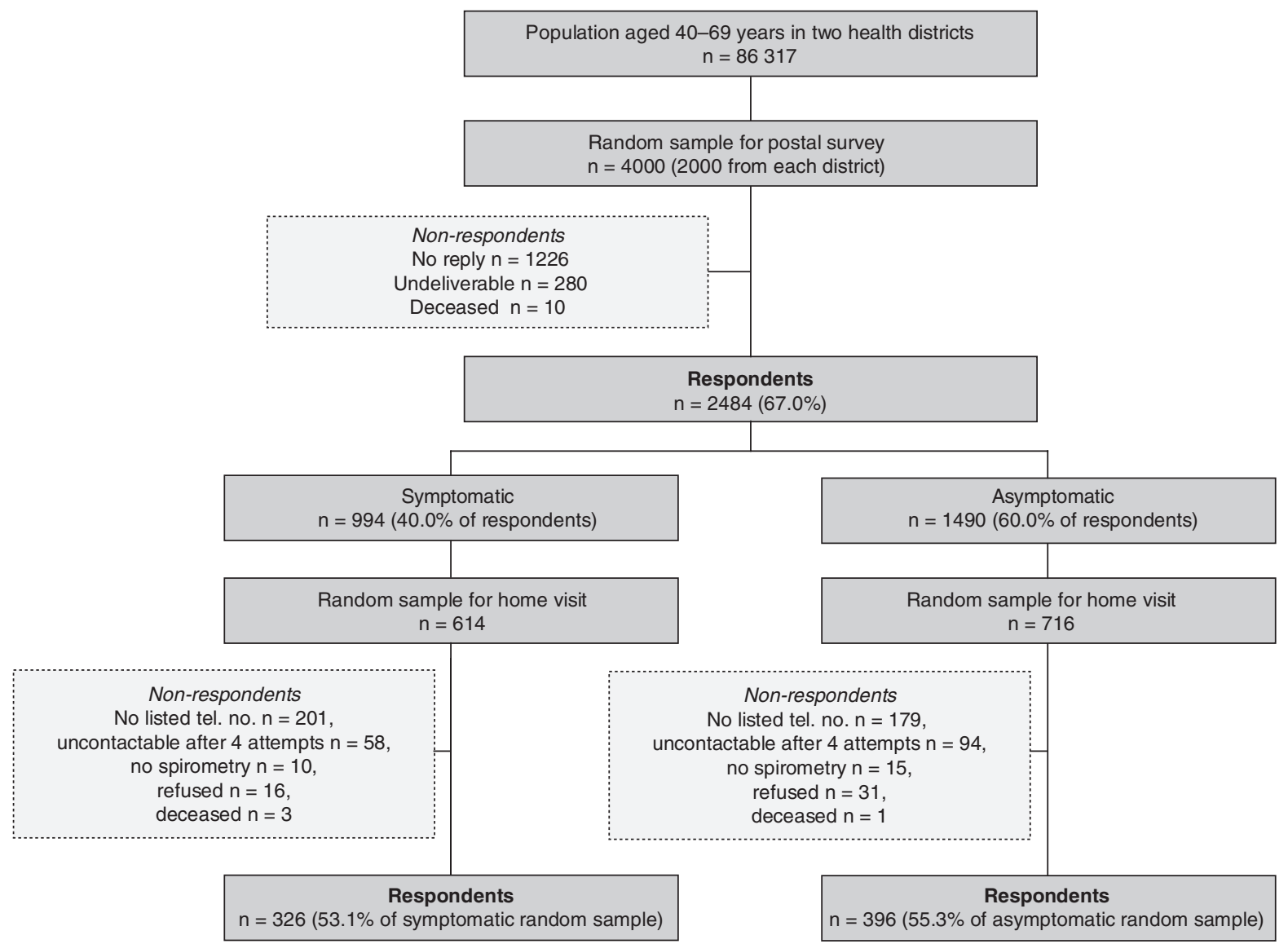

Fig. 1. Patient recruitment in the NICECOPD((Author: please define - National Institute for Health and Clinical Excellence? http://www.nice.org.uk)) study.((Author: please provide a reference))

ry, use of medication and health services, smoking history, occupation, and social status. Height and weight were measured. Spirometry was performed with the Vitalograph ((Author: is this a trade name - please provide city and manufacturer)) 'Gold Standard' bellows device in accordance with the British Thoracic Society (BTS) guidelines. Patients were asked to omit bronchodilator inhalers for 12 hours prior to assessment. Baseline spirometry was taken as the best $\mathrm{FEV}_{1}$ and best FVC of three technically satisfactory readings. The reference values established by Quanjer et al. ${ }^{[26]}$ were used. Airflow obstruction was defined as $\mathrm{FEV}_{1} / \mathrm{FVC}$ ratio of $<70 \%$, with $\mathrm{FEV}_{1}<80 \%$ predicted. Reversibility to $\beta_{2}$-adrenoceptor agonists ( $\beta_{2}$-agonists) was tested by repeating spirometry 15 minutes after inhalation of albuterol (salbutamol) $400 \mu \mathrm{g}$ through a large volume spacer. Reversibility was defined as an increase in $\mathrm{FEV}_{1}>200 \mathrm{~mL}$ and $15 \%$ greater than pre-bronchodilator value. After adequate instruction, patients were asked to record serial peak flows morning and evening for 2 weeks. Skin prick allergy testing was performed using extracts of house dust mite, cat, dog, grass mix and aspergillus, histamine, and a negative control. Subjects were asked to complete the EuroQol((Author: please define)) questionnaire. ${ }^{[27]}$

\section{Diagnoses}

A physician reviewed data for each patient, and a clinical diagnosis was assigned. Possible diagnoses included 'asthma', 'COPD' and 'indeterminate airflow obstruction'. A diagnosis of asthma required spirometric evidence of airflow obstruction with reversibility of $\mathrm{FEV}_{1}>15 \%$ following the administration of a $\beta_{2}$-agonist, \pm peak flow variability $>15 \%$, in the context of symptoms of attacks of wheezing associated with dyspnea, regular or nocturnal cough, or diurnal variation of symptoms. A diagnosis of COPD required airflow obstruction on spirometry with reversibility $<15 \%$, with peak flow variability $<15 \%$, in the context of a smoking history and regular symptoms of dyspnea, cough and wheeze, which did not show diurnal variability. Patients with airflow obstruction and no reversibility who had symptoms suggesting asthma earlier in life were labeled as asthma rather than COPD. After this review, 57 individuals had a diagnosis of asthma, 49 a diagnosis of COPD, and 7 were labeled as 'indeterminate airflow obstruction'. 
Detailed information relating to healthcare utilization in the past 12 months, the impact of the disease on the individual's overall quality of life, activities of daily life and socioeconomic conditions was elicited. Measures of healthcare utilization included details of medications, general practitioner visits, and hospital usage (outpatient and inpatient). Respondents were asked about healthcare utilization and healthcare accessed solely in relation to breathlessness. With regard to medications, respondents were asked to identify medications they regularly took as a result of breathlessness.

Healthcare costs were calculated using standard references, i.e. unit costs of health and social care ${ }^{[28]}$ in respect of the various services utilized (e.g. general practitioner visits and hospital visits); the British National Formulary ${ }^{[29]}$ was used in respect of prescribed medications. The same descriptive statistics were calculated regarding the various health services used.

\section{Statistical Methods}

Data are presented as mean with standard deviation and accompanying range. None of the cost data variables were normally distributed, and most had median values of 0 . Comparative analyses were performed using Mann Whitney $U$ tests for nonparametric data. Correlations were tested using nonparametric methods (Kendall's Tau). The regression analyses were undertaken using various transformations of the dependent variable (total cost) and specifications of independent variables. Those presented showed a square root transformation of total cost and linear versions of explanatory variables.

\section{Results}

An examination of cost data revealed the existence of three outliers within the asthma group One patient spent 90 days in hospital compared with an average of 2.5 days, another reported 50 general practitioner visits compared with an average of 6.33 , and one patient accounted for all nursing auxiliary visits by asthma patients. Inclusion of these three patients would in each instance substantially raise the mean costs and they were therefore excluded from the analysis. Descriptive statistics on a range of patient characteristics for the two groups are presented in table I. COPD patients were more likely to be male and to have smoked in the past. COPD patients also had significantly lower \% predicted $\mathrm{FEV}_{1}$ consistent with a greater degree of airflow limitation. Despite lower lung function, EuroQol scores were higher in COPD than asthma. With regard to prior physician diagnosis, $73.5 \%$ of patients with COPD had not been previously diagnosed compared with $15.8 \%$ of patients with asthma.
Table I. Descriptive statistics of patients diagnosed with COPD or asthma after a home visit (for diagnostic definitions see text((Author: please provide specific cross-reference))). Data are presented as mean (SD)

\begin{tabular}{|c|c|c|c|}
\hline Parameter & COPD $(n=49)$ & Asthma $(n=54)$ & $\mathrm{p}$-Value \\
\hline Male (\%) & 71.4 & 46.3 & $<0.01$ \\
\hline Age $(y)$ & $58.02(7.91)$ & $58.52(8.83)$ & $\begin{array}{l}\text { Difference } \\
\text { not } \\
\text { significant } \\
\text { (NS) }\end{array}$ \\
\hline Body mass index & $27.86(4.58)$ & $27.44(5.59)$ & NS \\
\hline$\%$ Predicted FEV 1 & $63.82(15.04)$ & $69.83(19.71)$ & $<0.1$ \\
\hline$\%$ Ever smokers & 86 & 58 & $<0.01$ \\
\hline EuroQol score ${ }^{a}$ & $0.81(0.21)$ & $0.65(0.40)$ & $<0.01$ \\
\hline Number of school years & 11.06 & $10.98(3.19)$ & NS \\
\hline
\end{tabular}

a Quality of life was calculated using the EuroQol descriptive system score, a generic quality of life measure comprising five dimensions of health (mobility, self-care, usual activities, pain/discomfort, anxiety/ depression). Each dimension comprises three levels (some, moderate, extreme problems), generating a total of 243 theoretically possible health states. These states can be converted into a weighted health state index by applying scores from 'value sets' elicited from general population samples

Descriptive statistics on the various components of healthcare costs for COPD and asthma patients are presented in table II. In each instance, average costs were higher among asthma patients than among COPD patients. Significant differences in respect of inhaler costs, all drug costs and total costs were observed.

A series of bivariate correlations between various components of cost and patient characteristics are presented in table III. In COPD patients, $\%$ predicted $\mathrm{FEV}_{1}$ was significantly correlated with several aspects of cost, as was school years. As \% predicted $\mathrm{FEV}_{1}$ fell, so general practitioner, drug and total costs tended to rise; as school years rose, so drug and total costs also fell. In asthma patients, smoking status, years of schooling and EuroQol score were significantly correlated with any of the measures of cost. Smoking was positively correlated with hospital, general practitioner and total costs; EuroQol score was negatively correlated with hospital costs; and general practitioner costs and school years were negatively correlated with general practitioner costs.

In table IV the results of a multivariate analysis of total costs regressed on various patient characteristics for the two patient groups are reported. To improve functional form, the total costs were transformed to their square root before running the regression. In the case of patients with COPD, while the percentage of the total variation in cost that is explained by the independent variables may be small $\left(r^{2}=0.34\right)$, the relationship is significant, as are two of the independent variables (\% predicted $\mathrm{FEV}_{1}$ and EuroQol score). Both these variables are negatively related to 
Table II. Descriptive statistics on patient costs. Data are presented as mean (SD), with range also given. All costs are shown as pounds sterling for the preceding 12 months((Author: please specify year of costing and currency here)). All comparisons were made using the Mann-Whitney $\mathrm{U}$ test

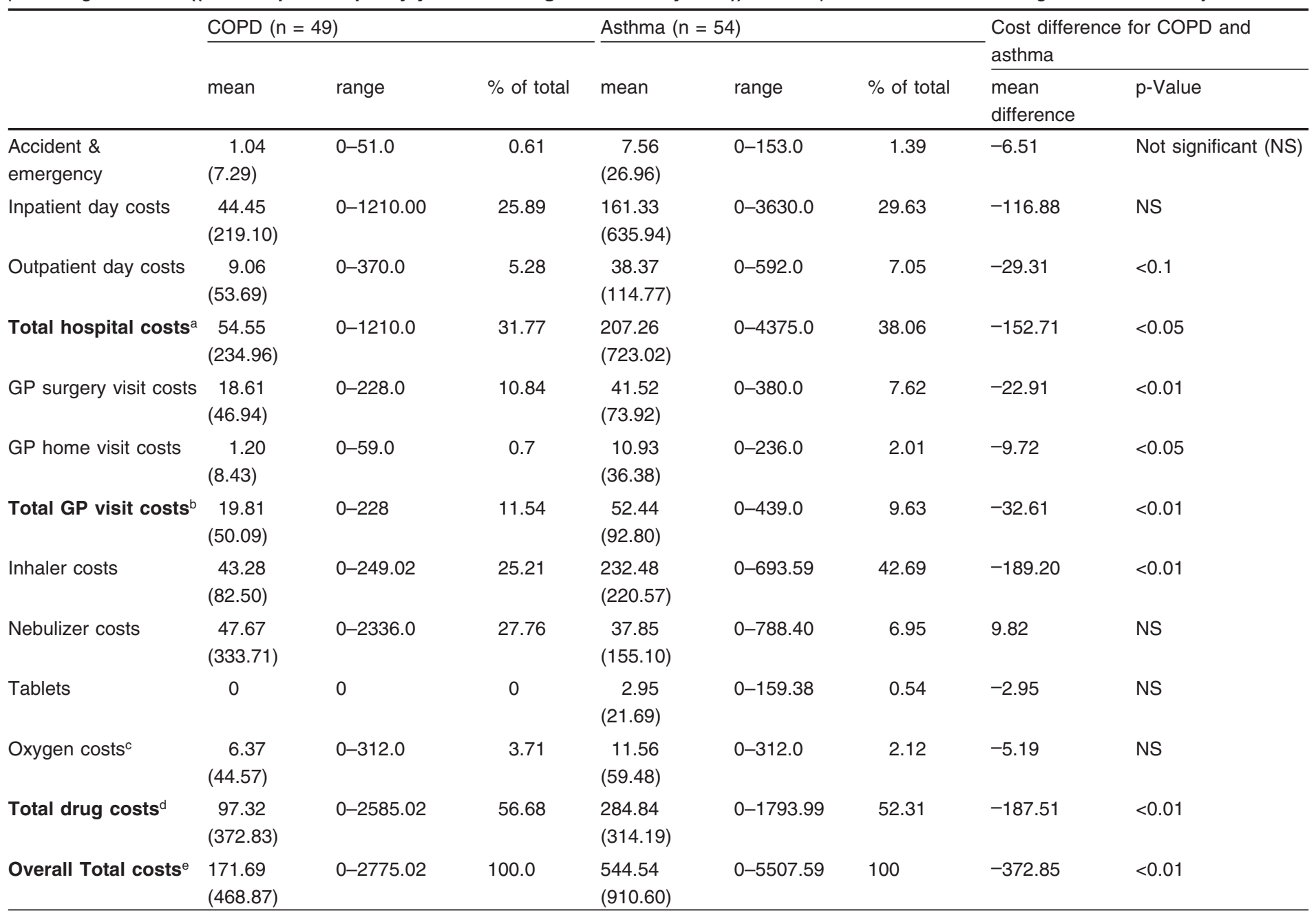

a Hospital costs represent the sum of accident and emergency, inpatient day and outpatient day costs.

b GP visit costs are the sum of both home and surgery visit costs.

c All patients were assumed to use oxygen concentrators rather than cylinders.

d All drug costs were defined as the sum of inhalers, nebulizers, systemic corticosteroid and nonsteroidal tablets (for airways disease), and oxygen costs.

e Total costs were defined as the sum of all drug costs, hospital and general practitioner (GP) visit costs.

overall costs. Alternative specifications of the model using current smoking patterns rather than 'ever having smoked' as independent variables as well as logarithmic transformations of cost and \% predicted $\mathrm{FEV}_{1}$ were examined. While these marginally increased the explanatory power of the function with respect to patients with COPD, conclusions remained unchanged (results not presented). In asthma patients the overall regression relationship was only marginally significant, as indicated by the F-statistic being significant only at the $90 \%$ level of confidence.

\section{Discussion}

The cost estimates in this study are based on a representative community-based sample in which the diagnoses of asthma and COPD have been well characterized and include asymptomatic and undiagnosed individuals. Given that effective disease-modifying treatment is available for asthma and not COPD, it not surprising that less is spent on drug therapy for COPD across the spectrum of severity. It is accepted that a high proportion of the cost of COPD is incurred by those with severe disease, ${ }^{[30]}$ who are not well represented in this study. At present, smoking cessation is 
Table III. Univariate correlations between patient characteristics and elements of cost. All correlations were performed using Kendall's Tau((Author: please confirm all entries in this tbl are correct.))

\begin{tabular}{|c|c|c|c|c|c|c|c|c|}
\hline \multirow[t]{2}{*}{ Parameter } & \multicolumn{4}{|c|}{ COPD $(n=49)$} & \multicolumn{4}{|c|}{ Asthma $(n=54)$} \\
\hline & hospital & GP costs & drug costs & total costs & hospital costs & GP costs & drug costs & total costs \\
\hline Male & -0.16 & 0.06 & 0.09 & 0.10 & -0.04 & -0.11 & 0.13 & -0.02 \\
\hline Age $(y)$ & 0.08 & -0.07 & -0.11 & -0.08 & 0.07 & 0.03 & 0.07 & 0.02 \\
\hline Body mass index & -0.06 & -0.06 & -0.03 & -0.09 & $-0.19^{\star}$ & 0.00 & 0.04 & -0.01 \\
\hline$\%$ Predicted FEV 1 & -0.07 & $-0.39^{\star \star \star}$ & $-0.32^{\star \star}$ & $-0.36^{\star \star \star}$ & -0.15 & 0.09 & 0.03 & 0.05 \\
\hline Smokers ${ }^{a}$ & 0.10 & 0.21 & 0.12 & 0.17 & $0.30^{\star *}$ & $0.25^{\star \star}$ & 0.14 & $0.20^{*}$ \\
\hline EuroQol score & -0.05 & -0.14 & -0.17 & -0.17 & $-0.29^{\star \star *}$ & $-0.23^{\star \star *}$ & 0.02 & -0.13 \\
\hline Number of school years ${ }^{b}$ & -0.17 & -0.13 & $-0.31^{* * *}$ & $-0.25^{\star *}$ & -0.11 & $-0.25^{\star *}$ & 0.03 & 0.08 \\
\hline
\end{tabular}

a One individual was omitted from the analysis as no data was recorded for this patient on ever having been a smoker.

b One individual was omitted from the analysis as no data was recorded for the number of school years this patient had completed.

GP = general practitioner. * $p<0.01 ;{ }^{* *} p<0.05 ;{ }^{* \star *} p<0.01$

the only known effective disease-modifying strategy in COPD, but much research is taking place developing new drugs for the treatment of COPD. The application of effective therapy for disease progression could increase costs considerably in the short term in the less severe categories of COPD. In addition, the prevalence of COPD is likely to continue to increase as the population ages, which will have an impact on costs.

Taking the two diseases separately, average annual costs per patient with COPD are generally lower in the present study than have been reported elsewhere in the literature, ((Author: please provide references)) though some care is warranted in making comparisons. As noted above and recognized by Guest, ${ }^{[22]}$ estimates of costs associated with COPD in the UK are likely to exhibit downward bias due to higher unit costs, making compari-

Table IV. Estimated coefficients after multivariate regression analysis, with the dependent variable being total cost for COPD and asthma patients

\begin{tabular}{|c|c|c|}
\hline & $\operatorname{COPD}(n=49)$ & Asthma $(n=54)$ \\
\hline Age $(y)$ & -0.13 & 0.24 \\
\hline Male & -0.19 & 0.91 \\
\hline Body mass index & 0.17 & -0.24 \\
\hline$\%$ Predicted $\mathrm{FEV}_{1}$ & $-0.34^{* *}$ & 0.06 \\
\hline EuroQol score & $-16.84^{\star *}$ & -1.45 \\
\hline Smoker & 2.19 & $9.70^{\star * *}$ \\
\hline Constant & $42.72^{*}$ & -2.09 \\
\hline $\begin{array}{l}F((\text { Author: please } \\
\text { specify what } F \\
\text { represents.)) }\end{array}$ & $3.68^{* \star \star}$ & $1.86^{*}$ \\
\hline $\begin{array}{l}r^{2}((\text { Author: please } \\
\text { specify what } r \\
\text { represents.)) }\end{array}$ & 0.34 & 0.20 \\
\hline
\end{tabular}

sons (even adjusting for inflation) somewhat difficult. In relation to other estimates, Ward et al. ${ }^{[11]}$ using year 1994 prices estimated total healthcare costs per year at \$US6.6 billion for COPD in the US. Given an estimated 15 million persons with $\operatorname{COPD}^{[11]}$ this translates to an average annual cost per patient, in year 1994 prices, of \$US440; i.e. \$US502 in year 2000 prices assuming inflation in healthcare prices of $14.1 \%$ between 1994 and 2000 . This compares with the \$US309 (assuming an exchange rate of $£ 1$ = \$US1.80((Author: year 2000 value?))) estimated here. However, the Ward estimate included elements of cost not included here, such as nursing home stays (which were occasioned by some of his study participants) as well as aspects of cost-related co-morbidities.

With respect to other studies the divergence is somewhat wider. Hilleman et al., ${ }^{[12]}$ for example, again in the US, estimated average costs per patient year among stage 1 COPD patients at \$US1681 (year 1999 prices), or approximately \$US1731 (year 2000 prices) assuming inflation of $3 \%$. Confining the comparison solely to stage 1 patients in our sample, costs were approximately \$US49 per year (cost estimates by Hilleman et al. ${ }^{[12]}$ and Pelletier-Fleury et al. ${ }^{[21]}$ for COPD patients with greater degrees of disease severity are not particularly meaningful for comparison given the very small numbers of patients with these degrees of disease severity in the present study). Again though, care is warranted given our exclusion of indirect costs((Author: sense? Please rework sentence for better clarity)). Sensitivity analyses where we relax our assumption regarding least cost use of oxygen therapy ${ }^{[27]}$ narrow the gap between our cost estimate and those of Ward et al. ${ }^{[11]}$ and Hilleman et al. ${ }^{[12]}$ Thus, assuming cylinder use at ((Author: please indicate year of estimates)) $£ 667.74$ per annum per patient, rather than concentrator use at $£ 312.40$ per annum, gives a mean costs per patient per annum of $£ 92.62$ (standard deviation = 
$£ 251.59$ ((Author: please confirm this entry is correct))), or \$US167 (standard deviation $=\$ 453$ ((Author: please confirm this entry is correct))). Comparing estimates of oxygen therapy in this study with those of Britton, ${ }^{[23]}$ they are seen to be considerably lower than their estimate of $£ 819$ ((Author: mean costs per patient per annum?)). In part this may be explained by differences in the sample populations recruited, with Britton, for example, selecting an older group of individuals with more severe disease $(26.5 \%$ being rated as having severe and $45 \%$ moderate COPD). In addition, the assumptions used by the latter((Author: Britton?))in estimating costs may also play a role. For instance, the consumption of a particular service at a specific level is assumed to accompany the reported consumption of other services.

In the case of asthma, costs per patient in the US were estimated by Smith et al. ${ }^{[14]}$ in year 1994 dollars at approximately \$US1302, based on an affected adult population of 2.7 million. Assuming inflation at $3.5 \%$ per annum over the intervening period, this translates to a cost per person in year 2000 dollars of approximately \$US1600. Assuming again an exchange rate of $£ 1=\$ U S 1.80$, our estimate translates to approximately \$US998 per patient. The estimate from Mellis et al. ${ }^{[18]}$ of \$US769 ((Author: please confirm this is \$US and not \$Aus)) per person in New South Wales, Australia, in 1989 translates to a cost in year 2000 dollars of \$US1123, though they concede this may be an underestimate; estimates by Unger et al. ${ }^{[30]}$ in Canada of \$US1275((Author: please confirm this is \$US and not \$Can)) per year in direct costs (year 1998 values) are again broadly comparable with our estimate.

COPD patients cost approximately $£ 373$ (\$US671) less on average per person per annum in direct medical costs than do asthma patients (table II). The bulk of this difference relates to greater expenses associated with inhalers and inpatient stays, which together comprise approximately $80 \%$ of the cost difference. The degree of fixed airflow obstruction does not predict the difference in costs: \% predicted FEV 1 was lower in COPD. However, EuroQol score was lower (i.e. self-assessed quality of life was poorer) in asthma and there was greater use of general practitioner services, which might result in increased drug use and hospital referrals. (As seen from table II, all aspects of general practitioner costs are higher in asthma patients.) Furthermore, a cost difference could also be explained if there was a bias for recognizing and treating asthma over COPD among general practitioners.

Our exploratory analysis of factors predicting cost within the two groups is crude, explaining roughly one-quarter of the total variation in asthma costs and one-third of the variation in COPD costs. In respect of COPD, as \% predicted $\mathrm{FEV}_{1}$ increases total direct costs fall, though the relationship is non-linear (around the level of average costs [£171] each percentage point increase in predicted $\mathrm{FEV}_{1}$ is associated with a fall in total costs of approximately £9 [approximately \$US16.20]. This finding is consistent with that of others where treatment costs have similarly been seen to increase with disease severity ${ }^{[11,21]}$ and with intuition((Author: what exactly do you mean by intuition)). In asthma no significant relationship was found between treatment cost and disease severity as determined by $\mathrm{FEV}_{1}$; however, the lower overall explanatory((Author: please confirm the word 'explanatory' is appropriate here)) power of the model used in this study and its marginal overall significance (as evidenced by the lower F-statistic) must be taken into account

\section{Conclusion}

This main strengths of this study are its community base of patients and the accuracy of diagnosis of asthma and COPD. In this setting, asthma costs more than COPD, which may relate in part to a relative under-diagnosis of COPD. As anticipated, the cost of COPD increases as $\mathrm{FEV}_{1}$ decreases but costs of asthma are not predicted by FEV1. We were able to explain one-third of the costs of COPD and a quarter of the costs of asthma. The database will enable modeling of the cost consequences of disease-modifying interventions such as smoking cessation programs, and increased diagnosis and better management of COPD.

\section{Acknowledgments}

The authors would like to acknowledge Glaxo Smith Kline and the Eastern Health and Social Services Board for providing support for the study. The authors have no conflicts of interest that are directly relevant to the content of this article.

\section{References}

1. ((Author: please provide full details, including date accessed))http://www.niceorg.uk/ [Accessed ]

2. American Thoracic Society. Standard for the diagnosis and care of patients with chronic obstructive pulmonary disease. Am J Resp Crit Care Med 1995; 152: S77-S120

3. Fletcher D, Peto R, Tinker C, et al. The natural history of chronic bronchitis and emphysema: an eight year study of early chronic obstructive lung disease in working men in London. Oxford: Oxford University Press, 1976

4. Bergner M, Hudson LD, Conrad DA, et al. The cost and efficacy of home care for patients with chronic lung disease. Med Care 1988; 26: 566-79

5. Sherrill DL, Lebowitz MD, Burrows B. Epidemiology of chronic obstructive pulmonary disease. Clin Chest Med 1990; 11: 375-87

6. National Center for Health Statistics -Health E Stats [online]. Available from URL: www.cdc.gov/nchs/products/pubs/pubd/hestats/asthma/asthma.htm [Accessed 2002 Aug 13]

7. ((Author: please provide full details, including date accessed))http:// ginasthma.com [Accessed ]

8. Barbee RA, Murphy S. The natural history of asthma. J Allergy Clin Immunol 1998; 102: S65-72

9. ((Author: please confirm details))Benson V, Marano MA. (1993) Current estimates from the National Health Interview Survey. Washington, DC: National 
Centre for Health Statistics, Vital and Health Statistics 10(190), 1994. DHHS Publication No. (PHS) 95-1518

10. Singh GK, Matthews TJ, Clark SC, et al. Annual summary of births, marriages, divorces and deaths: United States, 1994; monthly vital statistics report (Vol. 43, No. 13). Hyattsville (MD): National Centre for Health Statistics, 1994

11. Ward MM, Javitz HS, Smith WM, et al. Direct medical cost of chronic obstructive pulmonary disease in the USA. Respir Med 2000; 94: 1123-9

12. Hilleman DE, Dewan N, Malesker M, et al. Pharmacoeconomic evaluation of COPD. Chest 2000; 118 (5): 1278-85

13. Asthma in adults fact sheet. American Lung Association website [online]. Available from URL: http://www.lungusa.org/ [Accessed 2005 Apr 18]

14. Smith DH, Malone DC, Lawson KA, et al. A national estimate of the economic costs of asthma. Am J Respir Crit Care Med 1997; 156 (3): 787-93

15. Weiss KB, Gergen PJ, Hodgson TA. An economic evaluation of asthma in the United States. N Engl J Med 1992; 326: 862-6

16. Szucs TD, Anderhub H, Rutishauser M. The economic burden of asthma: direct and indirect costs in Switzerland. Eur Respir J 1999; 13 (2): 281-6

17. Krahn MD, Berka C, Langlois $\mathrm{P}$, et al. Direct and indirect costs of asthma in Canada, 1990. CMAJ 1996; 154 (6): 821-31

18. Mellis CM, Peat JK, Bauman AE, et al. The cost of asthma in New South Wales. Med J Aust 1991; 155 (8): 522-8

19. Kiivet RA, Kaur I, Lang A, et al. Costs of asthma treatment in Estonia. Eur J Public Health 2001; 11 (1): 89-92

20. Rutten van-Molken MP, Feenstra TL. The burden of asthma and chronic obstructive pulmonary disease: data from The Netherlands. Pharmacoeconomics 2001; 19 Suppl. 2: 1-6

21. Pelletier-Fleury N, Lanoe JL, Fleury B, et al. The cost of treating COPD patients with long-term oxygen therapy in a French population. Chest 1996; 110 (2): 411-6

22. Guest JF. The annual cost of chronic obstructive pulmonary disease to the UK's National Health Service. Dis Manage Health Outcomes 1999; 5: 93-100
23. Britton M. The burden of COPD in the UK: results from the Confronting COPD survey. Respir Med 2003; 97 Suppl. C: S71-9

24. Murtagh E, Heaney LG, Gingles J, et al. The prevalence of obstructive lung disease in a general population sample: the NICECOPD study. Eur J Epidemiol 2005 May; 20 (5): 443-53

25. ((Author: is this an abstract or a letter?))Fletcher CM. Standardised questionnaire on respiratory symptoms: a statement prepared and approved by the MRC Committee on the Aetiology of Chronic Bronchitis (MRC breathlessness score). BMJ 1960; 2: 1665

26. Quanjer PH, Lebowitz MD, Gregg I, et al. Peak expiratory flow: conclusions and recommendations of a Working Party of the European Respiratory Society. Eur Respir J Suppl 1997; 24: 2S-8S

27. ((Author: please confirm details))EuroQol quality of life assessment (EQ5D). EuroQol Group, PO Box 4443, 3006 AK Rotterdam, The Netherlands

28. Netten A, Dennet J. Unit costs of health and social care 2000. Canterbury: PSSRU University of Kent at Canterbury (UK), 2000

29. ((Author: please provide names of authors/editors, and chapter title $\&$ page nos))British National Formulary. London: British Medical Association, 2000

30. Ungar WJ, Coyte PC, Chapman KR, et al. The patient level cost of asthma in adults in south central Ontario. Pharmacy Medication Monitoring Program Advisory Board. Can Respir J 1998; 5 (6): 463-71

Correspondence and offprints: Dr L.G. Heaney((Author: please confirm that you are happy for us to publish your e-mail address)), Level 8, Belfast City Hospital, Lisburn Road, Belfast, BT9 7AB, Northern Ireland.

E-mail: 1.heaney@qub.ac.uk 